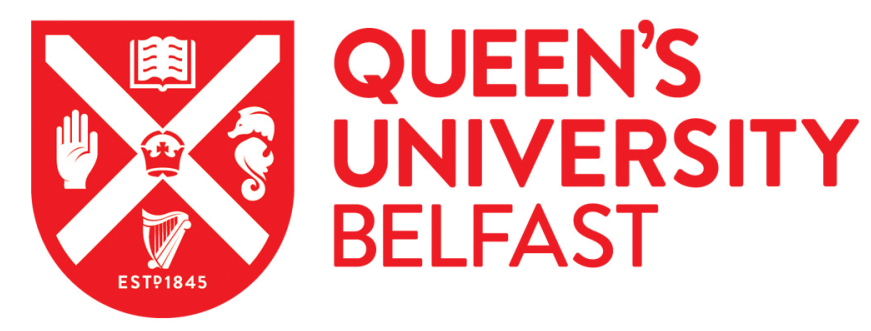

\title{
Preliminary evaluation of the Well-being in Pregnancy (WiP) Questionnaire
}

Alderdice, F., McNeill, J., Gargan, P., \& Perra, O. (2017). Preliminary evaluation of the Well-being in Pregnancy (WiP) Questionnaire. Journal of Psychosomatic Obstetrics and Gynecology, 38(2), 133-142.

https://doi.org/10.1080/0167482X.2017.1285898

Published in:

Journal of Psychosomatic Obstetrics and Gynecology

Document Version:

Peer reviewed version

Queen's University Belfast - Research Portal:

Link to publication record in Queen's University Belfast Research Portal

Publisher rights

Copyright 2017 Taylor \& Francis.

This work is made available online in accordance with the publisher's policies. Please refer to any applicable terms of use of the publisher.

\section{General rights}

Copyright for the publications made accessible via the Queen's University Belfast Research Portal is retained by the author(s) and / or other copyright owners and it is a condition of accessing these publications that users recognise and abide by the legal requirements associated with these rights.

Take down policy

The Research Portal is Queen's institutional repository that provides access to Queen's research output. Every effort has been made to ensure that content in the Research Portal does not infringe any person's rights, or applicable UK laws. If you discover content in the Research Portal that you believe breaches copyright or violates any law, please contact openaccess@qub.ac.uk. 


\section{Preliminary evaluation of the Well-being in Pregnancy (WiP) Questionnaire}

Fiona Alderdice ${ }^{1,2^{*}}$, Jenny McNeill ${ }^{1}$, Phyl Gargan ${ }^{1}$ and Oliver Perra ${ }^{1}$

${ }^{1}$ School of Nursing and Midwifery

Queens University Belfast

Medical Biology Centre

97 Lisburn Road

Belfast

Northern Ireland

BT9 7BL

${ }^{2}$ National Perinatal Epidemiology Unit

Nuffield Department of Population Health,

University of Oxford,

Old Road Campus, Headington,

Oxford OX3 7LF

*Corresponding author: f.a.alderdice@qub.ac.uk

j.mcneill@qub.ac.uk

p.gargan@qub.ac.uk

o.perra@qub.ac.uk 


\begin{abstract}
Background

The concept of well-being is multi-faceted by encompassing both positive and negative emotions and satisfaction with life. Measuring both positive and negative thoughts and emotions is highly relevant in maternity care that aims to optimise a woman's experience of pregnancy and childbirth, focusing on positive aspects of health and well-being, not just the prevention of ill health. Yet our understanding of well-being in pregnancy and childbirth is limited as research to date has focused on negative aspects such as stress, anxiety or depression. The primary aim of this study is to describe the psychometric properties of a newly developed Well-being in Pregnancy (WiP) questionnaire.
\end{abstract}

\title{
Methods
}

A cohort study of 318 women attending hospital antenatal clinics in Belfast completed a questionnaire including three general well-being measures (not pregnancy specific) and the newly developed WiP questionnaire. The psychometric properties of the questionnaire were analysed using correlations to explore the relationship between the WiP questionnaire with the generic well-being measures administered at the same time and exploratory factor analysis was conducted.

\section{Results}


The overall Cronbach's alpha of the WiP was 0.73. Principal factor analysis was run on the WiP items and two factors were identified, one reflecting positive affect and satisfaction (Cronbach's alpha $=0.718$ ) and the other concerns (Cronbach's alpha $=0.702)$. Both the overall WiP score and WiP sub-scale scores displayed significant correlations with the other well-being scales ( $r=0.235-0.527)$.

\section{Conclusions}

Measuring well-being in pregnancy is an important step in understanding the potential physical, psychological and social benefits of pregnancy and in understanding how well-being can be enhanced for women and their families at this important life stage. The initial psychometric data presented for the WiP questionnaire are encouraging. Most importantly, the measure provides an opportunity for women to express positive and negative emotions and thoughts about their pregnancy thus reflecting the whole spectrum of well-being.

\section{Key words}

Well-being, pregnancy, measurement, exploratory factor analysis, 


\section{Current Knowledge on the Subject}

- The concept of well-being is multifaceted consisting of positive and negative emotions and satisfaction with life

- Domain satisfaction and life satisfaction are generally highly correlated

- There is limited research focusing on positive aspects of psychological health and wellbeing during pregnancy.

\section{What this study adds}

- Reliability and validity of the WiP questionnaire were acceptable and two factors were identified: Positive Affect and Satisfaction factor and Concerns factor

- The WiP questionnaire was significantly associated with all general well-being measures

- This is an important step in facilitating research into the measurement of the whole spectrum of well-being not just poor psychological health. 


\section{Background}

Recent decades have seen a rapid increase in well-being research and a range of theoretical approaches to the study of well-being can now be drawn from a variety of disciplines ${ }^{1}$. There has been a growth in well-being measures and research into well-being across life domains such as school and work ${ }^{2,3}$. However the measurement of well-being in pregnancy and childbirth has remained underdeveloped. This is surprising as it is acknowledged that the aim of quality care during pregnancy is to optimize maternal and fetal health, to enhance women's experience of pregnancy and birth and to prepare women for motherhood whatever their risk status rather than simply focusing on ill health ${ }^{4}$.

Well-being is often conceptualized as a broad domain of interest rather than a specific construct $^{5}$. Specifically, it has been widely reported to consist of two distinctive affective and cognitive components ${ }^{6}$. Positive affect includes joy, interest, engagement, confidence and affection ${ }^{7}$. In addition, Diener and Emmons (1984) highlight the importance of measuring both positive and negative emotions in a full assessment of well-being ${ }^{8}$. The cognitive component is often referred to as Life Satisfaction. Huppert (2009) defines the cognitive component as involving the development of one's potential, having some control over one's life, having a sense of purpose (e.g. working towards valued goals), and experiencing positive relationships ${ }^{7}$. As the cognitive component reflects the conditions and circumstances of life as a whole, additional measurement of domain satisfaction can also be included. Domain satisfaction represents a focused evaluation of some specific aspect of one's life. In domain satisfaction, 
satisfaction is often measured by a small number of items on satisfaction within a larger social survey or in some cases by objective measures of finance, marital status or health. However this is perceived within the field to be a very limited interpretation of domain satisfaction ${ }^{1}$. There is limited agreement on what the core domains are that influence our well-being; researchers tend to agree that this includes family circumstances. Experience of pregnancy and childbirth is a major component of our family circumstances.

While domain satisfaction and life satisfaction are generally highly correlated, measurement of domain satisfaction allows the examination of variations in well-being related to specific circumstances. The need for a pregnancy specific measure is highlighted by the development of pregnancy-specific anxiety measures which have shown more predictive value than nonpregnancy specific measures ${ }^{9}$, 10 . Pregnancy specific anxiety may be more predictive as it assesses a recent time frame and is a major life event that potentially impacts on other aspects of life including relationship, health and life goals. Alderdice, Lynn and Lobel (2012) provide a review of measures that have been used to measure pregnancy specific stress and also those that have been used to predict premature birth ${ }^{11}$. A similar rationale can be used with pregnancy specific well-being measures and well-being research recognizes the unique contribution that a specific domain can bring to overall well-being ${ }^{1}$. Currently it is recommended that domain satisfaction be measured along with more general well-being measures to provide a more complete picture of well-being in this growing field of measurement ${ }^{5}$. 


\section{Well-being in pregnancy and childbirth}

The commitment to ensure women are empowered through control, choice and continuity, is outlined in maternity care documents internationally ${ }^{12,13}$, and provides an important foundation for enhancing well-being in pregnancy and childbirth. However measurement of the impact of maternity care to date has predominantly reported on satisfaction with services, which has limited interpretation ${ }^{14}$. In addition, intervention studies aimed at promoting health and well-being during pregnancy and childbirth have tended to use measures of stress, anxiety, self-esteem or self-efficacy ${ }^{11,15}$ rather than a multi-dimensional measure that allows the exploration of the impact of both positive and negative affect and thought. Evidence for a beneficial effect of positive emotions on physical health and survival ${ }^{16}$ and the knowledge that an individual's level of mental capital (cognitive and emotional resources) and psychological well-being is powerfully influenced by their early environment. Huppert (2009) ${ }^{7}$ highlights the need to comprehensively assess well-being in pregnancy. The aim of this study is to describe the properties of the Well-being in Pregnancy (WiP) measure and to describe how it relates to general well-being measures.

\section{Methods}

Design: cohort study.

Setting: Women were recruited at The Royal Jubilee Maternity Service located within the Belfast Health and Social Care Trust (BHSCT) in Northern Ireland. There are approximately 5560 
births per annum on the Royal Jubilee Maternity Service site (one of two maternity hospitals within the Belfast Trust).

Participants: 318 primiparous and multiparous women attending hospital antenatal clinics. Both low risk and high risk women attended antenatal clinics in the hospital as part of routine antenatal care in Northern Ireland at time of data collection. Recruitment was based on consecutive attendances at routine antenatal clinics in the hospital over a two week period in July 2011.

Inclusion criteria: Currently pregnant, over the age of 16 years old and attending a hospital based antenatal clinic.

Exclusion criteria: Does not adequately understand written English or has special communication needs.

Sample size: A formal sample size calculation was not conducted as the study is not comparative in nature. However studies with these aims typically recruit between 100 and 300 participants ${ }^{17}$ and a sample of 300 is recommended to establish meaningful psychometric $\operatorname{data}^{18}$.

\section{Pregnancy specific well-being questionnaire:}

Three focus groups were conducted to identify the aspects of pregnancy that impact on positive and negative affect and satisfaction. Two groups were with women who had recently given birth ( $n=9$ and $n=10)$ and one with women who were pregnant $(n=9)$. Twenty eight women participated in the focus groups; the majority were postnatal (68\%), married/living with a 
partner $(92.6 \%)$, had basic qualifications $(46 \%)$ or a university qualification (39\%) and all were born in the UK or Ireland.

Participants in the focus groups completed the European Social Survey Well-being Questionnaire and were asked about their impression of the questionnaire. Women were then asked about their well-being in pregnancy: what makes/made you happy, what is/ was bad or made you unhappy about pregnancy. Women's responses were categorized into themes (table 1). Information from descriptive studies of women's experiences of pregnancy and antenatal care that were ultimately included in a review of pregnancy specific stress measures ${ }^{11}$ were also used to facilitate question development. The questionnaire was tested further on five pregnant women for clarity and content and no changes were required.

Insert Table 1 here

The questionnaire is made up of 12 pregnancy-specific items building on the focus group themes. The experience of health professionals theme was developed into two questions to highlight the satisfaction and support aspects of care. Women were asked to respond using a 6 point questionnaire ranging from 'all the time' to 'at no time'. The timeframe was 'experience during current pregnancy' (further information on questionnaire development can be found in supplementary file 1).

General Well-being Measures: Three general measures were included to explore the convergent validity of the WiP Questionnaire: 
European Social Survey Well-being Questionnaire (ESSWQ). This general well-being measure reported and adapted from Michaelson et al. (2009) is made up of six key components: emotional well-being, satisfying life, vitality, resilience and self-esteem, positive functioning and social well-being ${ }^{20}$. The questionnaire was part of a large social survey and reliability and validity data were not reported for the scales. There were 38 items with four different response scales: a four point or six point response questionnaire from 'not at all' to 'all the time' was used for items such as 'How much time in the past week were you happy?' , a 10 point scale from 'not at all satisfied' to 'very satisfied' and a 5 point scale from 'strongly disagree' to 'strongly agree' for items such as 'How satisfied are you with life as a whole nowadays?'.

The Satisfaction With Life Scale (SWLS) ${ }^{21}$ is a five item scale developed to assess satisfaction with the respondent's life as a whole using a seven point scale from 'strongly agree' to 'strongly disagree'. Example items include 'In most ways my life is close to my ideal' and 'I am satisfied with my life'. It has good internal consistency (Cronbach's alpha reported to be between 0.79 and 0.89 ), moderate temporal reliability (test-retest reliability co-efficient are between 0.50 and 0.84 ) and is brief and easily incorporated into a larger research design. The neutral score is 20 with most groups having mean scores between 23-28 (mildly satisfied). The SWLS has been translated into a number of languages and has comprehensive psychometric data on a range of social and ethnic groups. Detailed reliability and validity data can be found in a review by Pavot and Diener, $2009^{22}$.

The WHO-5 Well-being Questionnaire ${ }^{23}$ is a short five item scale measuring positive psychological well-being within the past two weeks using a 6 point scale ranging from 'all of the 
time' to 'at no time'. Example items include 'My daily life has been filled with things that interest me' and 'I have felt cheerful and in good spirits'. Its psychometric properties have been demonstrated to be acceptable when used as a measure of well-being in different patient populations. The Cronbach's alpha has been reported as 0.91 and the measure has demonstrated convergent validity with measures of depression (e.g. Hospital Anxiety and Depression Scale -0.73).

Additional data were collected at the end of the questionnaire and included: gestation of pregnancy, age, level of education, marital status, ethnicity, self-reported health problems in pregnancy, previous experience of pregnancy and childbirth, and type of antenatal care. Followup data were collected from the Northern Ireland maternity electronic database (NIMATS) and included gestational age at birth, birthweight and admission to special care. Analysis of outcomes in relation to the WiP can be found in Supplementary File 2.

\section{Procedure:}

Following completion of ethics and research governance procedures (REC reference number 10/NIR01/24), an invitation and information leaflet was sent to all women attending antenatal clinics in the week prior to attendance to inform them about the study. Women interested in participating were given a consent form when they attended the clinic, consenting to complete the questionnaires and permitting access of their records for birth details at a later stage. The questionnaire was completed by women while waiting at the clinic. Data collection occurred over a two week period until the target sample of 300 women was recruited. Routine data were then obtained on each case after birth. 


\section{Data analysis}

In the first instance, an assessment of relevance and appropriateness of the items of each measure was conducted by exploring the incidence of missing item responses and the distribution of responses to items. Cases with missing data were excluded from the analyses. Internal consistency was assessed using Cronbach's alpha.

Correlations were conducted exploring the relationship between the WiP questionnaire with generic well-being measures administered at the same time. Exploratory factor analysis was conducted using STATA 12 (Principal Factor extraction, option pf): considering the ordinal nature of the item responses and in order to allow for non-normal distribution of responses in these items, factor analysis was conducted on the polychoric correlation matrix of the wellbeing in pregnancy items. Two set of statistics were considered in order to determine if there were sufficient numbers of significant correlations among the items to justify undertaking a factor analysis: the Kaiser-Meyer-Olkin (KMO) measure of sampling adequacy and the antiimage correlation matrix ${ }^{24}$. Following these tests for factorability, principal factor analysis was selected as the method of factor extraction and two decision rules were used to decide on which factors to retain; the Kaiser rule (minimum eigenvalue=1) and the scree test ${ }^{25}$. Oblique promax rotation was used as correlations between factors were suspected. Factor interpretation was guided by considering only variables with loadings greater than 0.32 as this reflects approximately $10 \%$ of variance in items in the factor: only loadings on a factor that were above this cut-off were considered 'significant' when defining a factor ${ }^{24}$. 


\section{Results}

Of 360 women who were invited to take part, 318 women completed the questionnaire (88\%). The majority completed the questionnaire in the third trimester, were multiparous, married/living with partner, between $26-35$ years of age, white European ethnic group, in good health and having shared antenatal care (see Table 2). No information was collected on women who did not consent to participate in the study and it is therefore not possible to investigate whether they differed from those taking part.

Insert Table 2

\section{Well-being in Pregnancy Questionnaire}

The measure comprised 12 items, with some item scales inverted to ensure higher scores corresponded to higher well-being. The mean and SD for each item and range of scores observed in each item is reported in Table 3.

Insert Table 3

A total score was obtained summing up the scores of each item (range 1-6) the distribution of total scores can be found in Figure 1. The mean score of the questionnaire was 51.47 with SD = 8.62, scores ranged between 31 and 72 and the data were normally distributed, displaying symmetry and no floor or ceiling effect observed.

Insert Figure 1

There was no difference in WiP scores across trimesters, by parity or marital status. Women who reported higher educational achievements (Degree or higher) displayed higher average 
scores in the questionnaire (mean $=52.65 ; \mathrm{SD}=8.12$ ) compared to women with other qualifications $($ mean $=50.71 ; S D=9.19)$ and those who left school without qualifications (mean $=50.68 ; \mathrm{SD}=6.85)$. However, these differences were not significant, $(F(2,309)=1.92, p=.15)$. Young women (20 years old or less) and women in the highest age band (over 40 years old) displayed lower average scores in the questionnaire (48.64 and 48.89 respectively) compared to women in other age bands (range 50.52 - 52.72): these differences were also not significant, $(F(5,311)=1.23, p=.29) ;$

The reliability of the questionnaire was investigated using Cronbach's alpha. The overall Cronbach's alpha for the questionnaire was 0.734 , which is above the 0.70 threshold considered to indicate an acceptable level of internal consistency ${ }^{26}$. The Cronbach's alpha for SWLS was 0.87 , WHO 0.84 and the ESS measure ranged between 0.69 Resilience and 0.92 Satisfying Life.

\section{Factor Analysis}

The overall Kaiser-Meyer-Olkin measure of sampling adequacy (KMO) was 0.70 , well above the level of 0.60 , which is considered the lower cut-off value indicating factorability of items ${ }^{27}$ : however, item 12 ("I feel supported by health professionals") had a value below this cut-off $(\mathrm{KMO}=0.54)$, while the $\mathrm{KMO}$ of the other items ranged between 0.61 and 0.80 . Inspection of the anti-image correlation coefficients matrix revealed that values in the off-diagonal were generally small, which concurred in indicating factorability of the items.

Only the first two factors in the un-rotated solution had values above 1: eigenvalues corresponding to these factors were 3.11 and 1.48 respectively, while the third factor had an 
eigenvalue of 0.95 . The scree plot also suggested retention of the first two factors: the slope of the scree plot changed substantially after the first two factors. The first two factors extracted explained respectively $58 \%$ and $28 \%$ of the variance observed, while the third factor explained $18 \%$ of variance observed. In successive analyses only two factors were extracted.

The solution was rotated using an oblique promax rotation and two factors were retained. A cut-off of loading equal to 0.32 was established for including a variable in the interpretation of a factor ${ }^{24}$. Loadings of items above this cut-off by factor are reported in Table 4 . The correlation between factors was $0.27(p=0.006)$. In the oblique promax rotation, factor 1 explained $53 \%$ of variance observed, and factor 2 explained $40 \%$ of variance. The items loading on Factor One were predominantly positively worded reflecting positive emotions, positive relationships and satisfaction with pregnancy and care. The items loading on Factor Two reflect concerns in pregnancy.

Insert Table 4

\section{Relationship of the two factors with other scales}

The exploratory factor analysis reported above suggested the presence of two factors. Factor 1 displayed loadings above .32 with items describing positive experiences during pregnancy (e.g. I feel I have bonded with my baby). Factor 2 displayed high loadings with items describing concerns about health and pregnancy outcomes (e.g. I am concerned about the health of my baby). Items that loaded on factor 1 were considered as indicators of a Positive Affect and Satisfaction scale. Items loading on Factor 2 were considered as indicators of a Concerns scale. As reported in the exploratory factor analysis, the correlation between the two factors was of 
small magnitude. Analyses also suggested that Item 12 ("I feel supported by health professionals") was the weakest one, as indicated by a low KMO value, weak loadings and a high uniqueness value and was excluded from further analyses.

We tested the internal consistency of the two sub-scales using Cronbach's alpha. The alpha of the first Positive affect and Satisfaction sub-scale was 0.718 . The alpha of the Concerns subscale was $0.702 \ldots$

Table 5 shows that both the overall WiP score and WiP sub-scale scores displayed significant correlations with the other well-being scales (ESS, WHO5, SWLS).

Insert Table 5 here

The common variance of the WiP and general well-being measures in relation to pregnancy and birth outcomes is explored in Supplementary File 2.

\section{Discussion}

Overall the WiP questionnaire demonstrated good reliability and validity. The Cronbach's alpha was in the acceptable range, and the questionnaire produced a total score with a normal distribution with no floor or ceiling effects. The convergent validity with general well-being measures showed significant correlations but correlations were not so high as to suggest they are the same construct. There was no difference in scores by parity or trimester in pregnancy. The exploratory factor analysis suggests that there may be two different constructs at play rather than a single well-being construct. This is in keeping with the finding of measuring positive and negative emotions in the general well-being literature and Diener and Emmons 
(1994) ${ }^{8}$ argues that positive and negative affect measures should be kept separate; hence the relationship with other measures and birth outcomes was presented separately for the two factors. A better reflection of well-being theory would have been a three factor solution with positive affect, negative affect and satisfaction loading on separate factors. However the satisfaction items all loaded on Factor 1. The analyses suggested that pregnant women could display positive feelings about their pregnancy (e.g. feeling of bonding with the baby) and concerns about the pregnancy (e.g. health concerns), with positive feelings and concerns being relatively independent from each other. However, there was a small but significant correlation between the two factors and further work is needed to explore if these are independent constructs or the same construct with relatively superficial variations in the positive and negative representation of the construct. In the future, we plan to investigate the structure of the underlying constructs more closely with different populations and methods (e.g. Confirmatory Factor Analysis).

The WiP showed expected relationships with other well-being measures. The mean scores of women during pregnancy in the study for the WHO5 are lower than those found in other studies in the general population ${ }^{23}$. This may largely be related to two of the five questions, 'I felt active and vigorous' and 'I woke up feeling fresh and rested', reflecting the physical impact of pregnancy rather than reflecting general well-being. Conversely, the mean SWLS score in this sample was higher than scores reported in other studies involving a range of non-pregnant populations ${ }^{22}$. Identifying the unique and common variance across types of well-being is an important avenue for future research in helping gain a better understanding of well-being in 
pregnancy. Regression models of pregnancy and birth outcomes (Supplementary File 2) suggest that there is considerable common variance between pregnancy specific and general stress measures. Also, the variations in general well-being scores reported in this study demonstrates the importance of considering the appropriateness of the measure to use in pregnant populations and the importance of further research on the potential impact of pregnancy on well-being taking into consideration the physical, psychological and social aspects of pregnancy.

The WIP questionnaire is short and easy to use in both research and practice. The questionnaire was developed based on feedback and views of pregnant and postnatal women in addition to current theory and research and it is important that women's views and experiences continue to be reflected in ongoing instrument development. It is also important to acknowledge that different approaches to measuring well-being in pregnancy exist that are evolving alongside general well-being theory. For example, using an established pregnancy specific measure of stress, anxiety or depression and also including measures of self-esteem or optimism may provide valuable insights into a woman's well-being during pregnancy ${ }^{29,}{ }^{30}$. The field is wide open for development, however for a well-being measure to be of clinical use in pregnancy it is important that it has strong theoretical foundations which are also well grounded in women's experience. Large, prospective studies exploring the relationship between well-being and a broader range of pregnancy and birth outcomes would help evolve our understanding of wellbeing. 
Having a measure that allows women to express both positive and negative thoughts and emotions provides important data on the spectrum of psychological health and supports policy initiatives that promote personalized care ${ }^{12}$. The WiP facilitates identification of specific aspects of pregnancy that women feel positively and negatively about that can facilitate care planning throughout pregnancy and birth. These questions provide a route into asking women in more detail about how their care may be tailored to support them were needed and also facilitates positive conversations with women about how care and experience of pregnancy may be enhanced further. While it is vital that we can identify women who require additional psychological support, we also need to acknowledge that the majority of pregnant women are well and have a positive experience during pregnancy. We need more research on the potential psychological benefits of this major life experience for mother, partner and baby rather than continually focusing on the negative ${ }^{31}$.

\section{Limitations}

The sample was a convenience sample and as a result there were fewer women in the sample who completed the questionnaires during the first and second trimesters of pregnancy. The lack of relationship between well-being and gestation in analyses could be affected by these smaller samples sizes. A further limitation in the sample, is that ineligible women and those who declined to participate may have differed from study participants and this, again, could affect findings and limit generalizability of findings. In regard to measurement, problems reported in pregnancy are self-reported and as such this variable is open to bias. Finally, the 
WiP questionnaire would also benefit from further item development, particularly the satisfaction items, to ensure the three key components of well-being are adequately reflected in the questionnaire.

\section{Conclusions}

Data from the study suggest that this short, self-report measure of well-being in pregnancy is promising for use in research and in practice. At this stage, more information on both generic and pregnancy specific measures is needed. Generic measures need to be thoroughly tested in pregnant women to explore the generalizability and relevance of the underlying assumptions and also to allow for comparison with other life stages. The WiP questionnaire requires further validation in terms of correlations with other measures and related constructs in diverse pregnant populations. However the initial psychometric data presented for the WiP questionnaire are encouraging. Most importantly, the measure provides an opportunity for women to express positive and negative emotions and thoughts about their pregnancy thus reflecting the whole spectrum of well-being.

\section{Acknowledgments}

We would like to thank all the women who participated in the study. 


\section{Declaration of interest}

The authors report no conflicts of interest. The study was funded by [blinded for review] 


\section{References}

1. Diener E. Assessing Subjective Well-being: Progress and Opportunities in Diener E (Ed) Assessing Well-being Social Indicators Research Series 2009 Number 39 Springer USA.

2. Scott Huebner E \& Diener C. Research on life satisfaction of children and youth: Implications for the delivery of school-related services in Eid M and Larsen R J The Science of Subjective Well-being 2008 The Guildford Press New York.

3. Verducci S and Gardner H. Good work: its nature, its nurture. In Huppert FA, Baylis N and Keverne B The science of well-being 2007 Oxford University Press Oxford UK.

4. National Institute for Health and Care Excellence. QS22 Quality Standard in Antenatal Care http://publications.nice.org.uk/quality-standard-for-antenatal-care-qs22 2012.

5. Diener, E, Suh EM, Lucas RE, Smith HL. Subjective well-being three decades of progress. Psychological Bulletin 199925 276-302.

6. Van Hoorn, A. A short introduction to subjective well-being: its measurement, correlates and policy uses. Conference proceedings for the Conference 'Is happiness measurable and what do those measures mean for policy? April 2007 University of Rome 'Tor Vergata'.

7. Huppert FA. Psychological Well-being: Evidence regarding its causes and consequences. Applied Psychology: Health and Well-being 200912 137-164.

8. Diener, E and Emmons RA. The independence of positive and negative affect. Journal of Personality and Social Psychology 198469 130-141. 
9. Lobel M, Cannella DL, Graham JE, DeVincent C, Schneider J, Meyer BA. Pregnancyspecific stress, prenatal health behaviors, and birth outcomes. Health Psychology 2008; 27 : 604-15. Doi:10.1037/a0013242.PubMed PMID: 18823187)

10. Dunkel-Schetter, C \& Glynn, L. Stress in pregnancy: empirical evidence and theoretical issue to guide interdisciplinary researchers. In Contrada, R. \& Baum, A (Eds.), Handbook of Stress ( $2^{\text {nd }}$ edition). 2008 New York: Springer publishing Company.

11. Alderdice F, Lynn F, Lobel M. A review and psychometric evaluation of pregnancyspecific stress measures. Journal of Psychosomatic Obstetrics and Gynecology 2012; 33: 62-77. doi:10.3109/0167482X.2012.673040

12. The National Maternity Review. Better Births: Improving outcomes of maternity services in England: A five year forward review for maternity care NHS England. 2016 https://www.england.nhs.uk/wp-content/uploads/2016/02/national-maternity-reviewreport.pdf

13. Angood PB, Armstrong EM, Ashton D, Burstin H, Corry MP, Delbanco S, Fildes B, Fox D Gluck PA, Gullo S L Howes J, Rima Jolivet R, Laube DW, Lynne D, Main E, Markus AR, Mayberry L, Mighcel LV, Ness DL, Nuzum R, Quinlan JD, Sakala C, Salganicoff A, Blueprint for Action: Steps Toward a High-Quality, High-Value Maternity Care System Women's Health Issues 20 (2010) S18-S49.

14. Teijlingen E R, Hundley V, Rennie AM, Graham W and Fitzmaurice A. Maternity satisfaction studies and their limitations: what is must still be best. Birth 2003; 30: 2 75-82. 
15. Alderdice, F and Lynn, F. Stress in pregnancy British Journal of Midwifery 2009; 17:9 552-559.

16. Pressman SD and Cohen S. Does positive affect influence health? Psychological Bulletin 2005 ; 131: 925-971.

17. Jomeen, J and Martin, CR. Is the Hospital Anxiety and Depression Scale (HADS) a reliable screening tool in early pregnancy? Psychology and Health 2004; $19 ; 787-800$.

18. Kline P. Handbook of Psychological Testing. $2^{\text {nd }}$ Edition.2000 Routledge New York.

19. Diener, E, Napa Scollon C, Lucase RE. The Evolving Concept of Subjective Well-being: The Multifaceted Nature of Happiness. In Diener E (Ed) Assessing Well-being Social Indicators Research Series 2009 Number 39 Springer USA.

20. Michaelson J, Abdallah S, Steuer, N, Thompson S, Marks N. National Accounts of Wellbeing: bringing real wealth onto the balance sheet 2009 London: nef.

21. Diener, E, Emmons R.A., Larsen, R.J., Griffin S. The Satisfaction with Life Scale, Journal of Personality and Social Psychology 1985; 47: 1105-1117.

22. Pavot W and Diener E. Review of the Satisfaction with Life Scale in Diener E (Ed) Assessing Well-being Social Indicators Research Series 2009 Number 39 Springer USA.

23. Bech P. Measuring the Dimension of psychological general well-being by the WHO5.Quality of Life Newsletter 200432 15-16.

24. Tabachnick B and Fidell L. Using Multivariate Statistics $5^{\text {th }}$ Edition 2007 Boston Allyn and Bacon. 
25. Cattell, RB. The scree test for the number of factors. Multivariate Behavioral Research 1966; $1: 245-276$.

26. Nunally, JC and Bernstein IH. Psychometric theory (3 ${ }^{\text {rd }}$ Edition). 1994 New York NY McGraw-Hill Inc.

27. Cerny, CA, Kaiser, HF. A study of a measure of sampling adequacy for factor-analytic correlation matrices. Multivariate Behavioral Research, 1977; 12:1 43-47.

28. Dunkel-Schetter C, Lobel M. Pregnancy and birth outcomes: A multi-level analysis of prenatal stress and birth weight. In Baum AS, Revenson TA, Singer JE. (Eds), Handbook of Health Psychology. 2010 Psychology Press USA.

29. Rini CK, Dunkel Schetter C, Wadhwa PD, Sandman CA. Psychological adaptation and birth outcomes: the role of personal resources, stress, and sociocultural context in pregnancy. Health Psychology 1999; 18:33-45

30. Lobel M, DeVincent CJ, Kaminer A, Meyer BA. The impact of prenatal stress and optimistic disposition on birth outcomes in medically high-risk women. Health Psychology 2000; 19: 544-53

31. Alderdice, F. Ayers, S, Darwin Z, Green J, Jomeen J, Kenyon S, Martin CR, Morrell J, Newham JJ, Redshaw M, Savage-McGlynn E, Walsh J. Measuring psychological health in the perinatal period: workshop consensus statement, 19 March 2013. Journal of Reproductive and Infant Psychology 2013; 31: 431-438. 
Table 1: Themes from focus groups

\begin{tabular}{|c|c|}
\hline 'Theme & Quotation \\
\hline $\begin{array}{l}\text { Response to general } \\
\text { well-being } \\
\text { questionnaire }\end{array}$ & $\begin{array}{l}\text { 'They were kind of important questions I thought ' } \\
\text { 'A bit biased in favour of people who don't have children' } \\
\text { 'I'd maybe tailor the sleep and social aspects ' } \\
\text { 'What was missing: I think worry, talking about worry, like I } \\
\text { worried an awful lot, ' } \\
\text { 'I was like worried over everything... niggle niggle everything ' } \\
\text { 'The question about physical activity you know - can't wait and } \\
\text { do a spinning class but haven't been able to do one for quite a } \\
\text { long [time]' }\end{array}$ \\
\hline Relationships & $\begin{array}{l}\text { 'That's my biggest worry of pregnancy is how its going to affect } \\
\text { my married life.' } \\
\text { 'You worry about how other people, how other people } \\
\text { perceive you and what you do afterwards' } \\
\text { 'Yes I worried about me and my partner' }\end{array}$ \\
\hline Giving birth & $\begin{array}{l}\text { 'Giving birth is in there ' } \\
\text { 'I would say you think about birth before you even get } \\
\text { pregnant....' } \\
\text { 'I'm just worried about getting it out.' } \\
\text { 'About the delivery and was everything going to be alright' }\end{array}$ \\
\hline My health & $\begin{array}{l}\text { 'Like thinking, oh, I can't lift that or I can't eat that and 'Is this } \\
\text { ok?' } \\
\text { 'The whole pregnancy was like a ticking time bomb the whole } \\
\text { time' }\end{array}$ \\
\hline $\begin{array}{l}\text { How I look in } \\
\text { pregnancy }\end{array}$ & $\begin{array}{l}\text { 'I do feel quite proud of my bump' } \\
\text { 'Because I am battling weight all the time, but when you're } \\
\text { pregnant you don't care' } \\
\text { 'I liked the bump, I felt so pretty' }\end{array}$ \\
\hline Physical symptoms & $\begin{array}{l}\text { 'I think the nauseousness was worse [than being sick]' } \\
\text { 'It was the tiredness that got me. I was floored by it ' }\end{array}$ \\
\hline
\end{tabular}




\begin{tabular}{|l|l|}
\hline & $\begin{array}{l}\text { 'My shoes wouldn't fit me or nothing' } \\
\text { 'I had a lot of fluid so I just felt quite fat' }\end{array}$ \\
\hline $\begin{array}{l}\text { Feelings about } \\
\text { pregnancy }\end{array}$ & $\begin{array}{l}\text { 'I enjoyed being pregnant' } \\
\text { 'I hated being pregnant' } \\
\text { 'You're the princess' } \\
\text { 'I would be pregnant all day long. All my life I would be } \\
\text { pregnancy' }\end{array}$ \\
\hline $\begin{array}{l}\text { Attachment baby } \\
\text { 'Youlth of baby }\end{array}$ & $\begin{array}{l}\text { 'With my second one I worried that I would not love him as } \\
\text { much as I loved the first one' } \\
\text { 'All of a sudden I went 'Am I going to want my baby?' ' }\end{array}$ \\
\hline $\begin{array}{l}\text { Eonfidence/sure of } \\
\text { care/health } \\
\text { professionals }\end{array}$ & $\begin{array}{l}\text { 'And that they're safe, that they're healthy' } \\
\text { 'IWorried] baby healthy...' }\end{array}$ \\
\hline purpose in life & $\begin{array}{l}\text { 'Well I was worried sick because they kept going 'Listen, you're } \\
\text { going to need a section' and I kept saying to them 'But I've } \\
\text { never had a baby before, how do you know?' } \\
\text { 'It was only till the doctor came and then he explained the } \\
\text { situation' } \\
\text { 'Why ask women what kind of birth plan they want when }\end{array}$ \\
\hline
\end{tabular}


Table 2: Characteristics of the Study Population ( $N=318)$

\begin{tabular}{|c|c|c|}
\hline Maternal Characteristics & $\mathbf{N}$ & $\%$ \\
\hline \multicolumn{3}{|l|}{ Mother's Age } \\
\hline 20 or under & 22 & 6.92 \\
\hline $21-25$ & 58 & 18.24 \\
\hline $26-30$ & 99 & 31.13 \\
\hline $31-35$ & 83 & 26.10 \\
\hline $36-40$ & 46 & 14.47 \\
\hline Over 40 & 9 & 2.83 \\
\hline Missing & 1 & 0.31 \\
\hline \multicolumn{3}{|l|}{ Mother's Marital Status } \\
\hline Single & 26 & 8.18 \\
\hline Married/Re-married & 173 & 54.40 \\
\hline Living with Partner & 113 & 35.53 \\
\hline Separated/Divorced & 6 & 1.89 \\
\hline \multicolumn{3}{|l|}{ Mother's Ethnic Group } \\
\hline White & 304 & 95.60 \\
\hline Other & 14 & 4.40 \\
\hline \multicolumn{3}{|c|}{ Mother's Highest Qualification } \\
\hline University & 124 & 38.99 \\
\hline A Level & 54 & 16.98 \\
\hline GCSE or NVQ & 109 & 34.28 \\
\hline No Qualifications & 25 & 7.86 \\
\hline Missing & 6 & 1.89 \\
\hline \multicolumn{3}{|c|}{ 'How would you rate your health' } \\
\hline 1.Very Poor & 2 & 0.63 \\
\hline 2 & 8 & 2.52 \\
\hline 3 & 63 & 19.81 \\
\hline 4 & 107 & 33.65 \\
\hline 5.Very Good & 135 & 42.45 \\
\hline Missing & 3 & 0.94 \\
\hline First Pregnancy & 125 & 39.31 \\
\hline
\end{tabular}




\begin{tabular}{|l|c|c|}
\hline $\begin{array}{l}\text { Self-reported Problems this } \\
\text { pregnancy }\end{array}$ & 103 & 32.39 \\
\hline $\begin{array}{l}\text { Pregnancy Trimester when } \\
\text { questionnaire was completed }\end{array}$ & & \\
\hline $1^{\text {st }}$ Trimester & 41 & 12.89 \\
\hline $2^{\text {nd } T r i m e s t e r ~}$ & 59 & 18.55 \\
\hline $3^{\text {rd } T r i m e s t e r ~}$ & 213 & 66.98 \\
\hline Missing & 5 & 1.57 \\
\hline & & \\
\hline Type of Care & & \\
\hline Shared & 210 & 66.04 \\
\hline Hospital & 71 & 22.33 \\
\hline Midwifery Led & 13 & 4.09 \\
\hline Private & 5 & 1.57 \\
\hline Don't Know & 17 & 5.35 \\
\hline & & \\
\hline Gestational age at birth & & \\
\hline $20-29$ weeks & 4 & 1.26 \\
\hline $30-37$ weeks & 33 & 10.38 \\
\hline $38+$ weeks & 230 & 72.33 \\
\hline Missing & 51 & 16.04 \\
\hline & & \\
\hline Birthweight & & \\
\hline$<1500 g$ & 5 & 1.87 \\
\hline $1500-2499 g$ & 16 & 5.99 \\
\hline $2500 g$ or more & 246 & 92.13 \\
\hline Missing & 51 & 16.04 \\
\hline & & \\
\hline Baby Admitted to Special Care & 18 & 5.66 \\
\hline Yes & 249 & 78.30 \\
\hline No & 51 & 16.04 \\
\hline Missing & & \\
\hline
\end{tabular}


Table 3: Mean and SD for each observed item on the Well-being in Pregnancy Scale $(n=318)$

\begin{tabular}{|l|l|l|}
\hline Item $^{1}$ & Mean & Standard Deviation \\
\hline I am satisfied with my experience of health care & 5.10 & 1.05 \\
\hline I feel I have bonded with my baby & 5.08 & 1.26 \\
\hline I feel very positive about being pregnant & 5.05 & 1.03 \\
\hline I feel supported by health professionals & 4.96 & 1.13 \\
\hline $\begin{array}{l}\text { I am concerned that my relationships are } \\
\text { changing }\end{array}$ & 4.67 & 1.54 \\
\hline I am happy with how I look in pregnancy & 4.37 & 1.42 \\
\hline Being pregnant has given me purpose in life & 4.23 & 1.63 \\
\hline I am concerned about my own health & 3.82 & 1.64 \\
\hline Physical symptoms upset me & 3.76 & 1.51 \\
\hline Being pregnant makes me feel confident & 3.59 & 1.55 \\
\hline I am anxious about giving birth & 3.52 & 1.68 \\
\hline I am concerned about the health of my baby & 3.32 & 1.75 \\
\hline
\end{tabular}

${ }_{1}^{1}$ Item response was on a Likert scale $1=$ all the time through to $6=$ at no time 


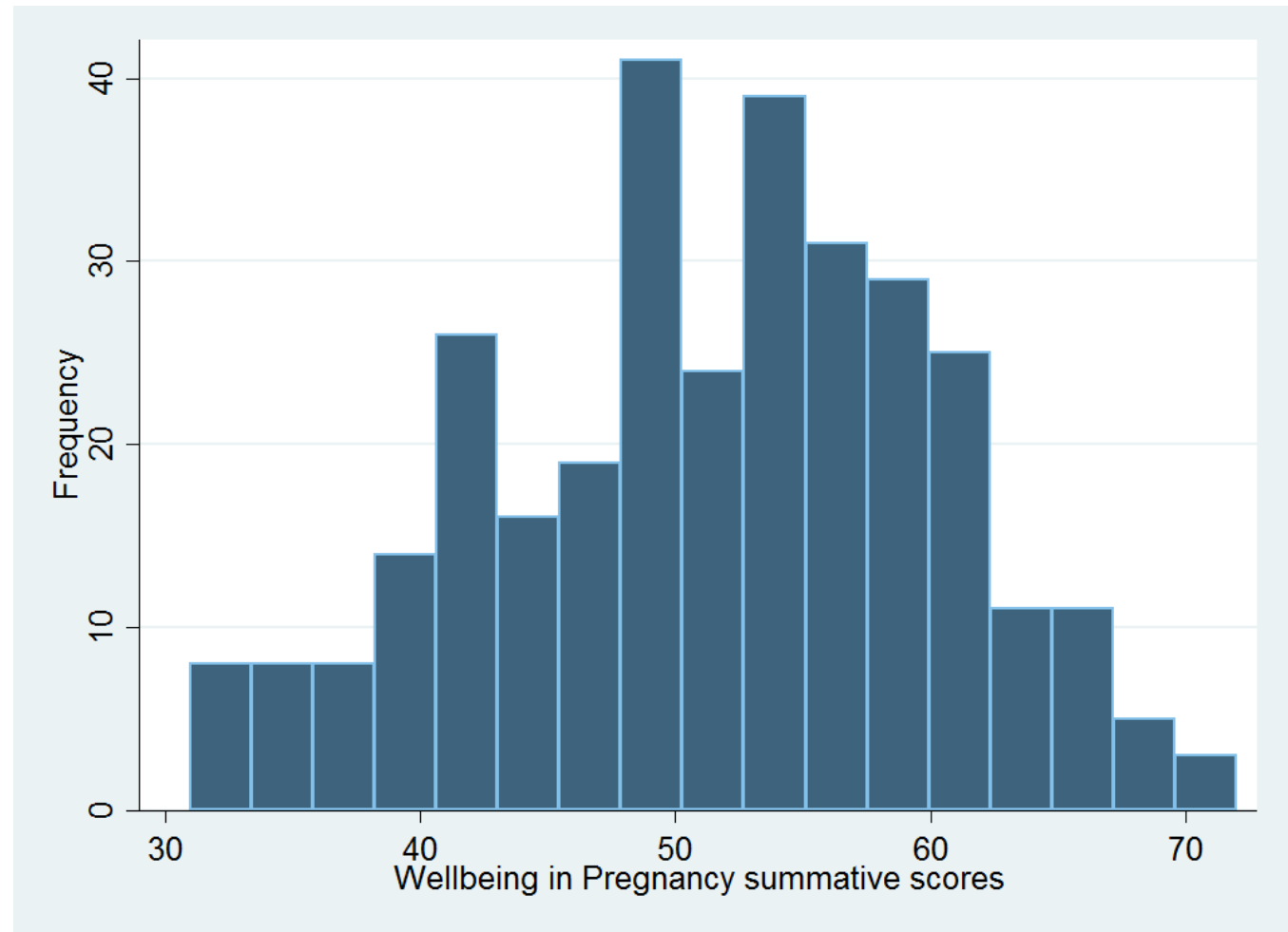

Figure 1: Distribution of summative scores for the WiP 
Table 4: Rotated factor loadings (pattern matrix) and unique variances

\begin{tabular}{|l|l|l|l|}
\hline Item & Factor 1 & Factor 2 & Uniqueness \\
\hline (1) I feel positive about being pregnant & 0.7209 & & 0.4139 \\
\hline (2) I feel I have bonded with my baby & 0.6508 & & 0.5794 \\
\hline (3) I am happy with how I look in pregnancy & 0.7429 & & 0.4482 \\
\hline $\begin{array}{l}\text { (5) I am satisfied with my experience of health } \\
\text { care }\end{array}$ & 0.4667 & & 0.704 \\
\hline (7) Being pregnant makes me feel confident & 0.7176 & & 0.4965 \\
\hline $\begin{array}{l}\text { (11) Being pregnant has given me purpose in } \\
\text { life }\end{array}$ & 0.4316 & & 0.8182 \\
\hline (12) Feel supported by health professionals & 0.3834 & & 0.832 \\
\hline $\begin{array}{l}\text { (4) I am concerned that my relationships are } \\
\text { changing }\end{array}$ & & 0.5367 & 0.6908 \\
\hline $\begin{array}{l}\text { (6) I am concerned about the health of my baby } \\
\text { (8) I am concerned about my own health }\end{array}$ & & 0.6794 & 0.5632 \\
\hline (10) I am anxious about giving birth & & & \\
\hline
\end{tabular}


Insert Table 5 


\section{Supplementary Information 1: Development of the WiP questionnaire:}

The WiP questionnaire development was led by the conceptual model of well-being that includes positive and negative affect and satisfaction. When including positive and negative affect in a measure, Diener et al (2009) recommend that general labels reflecting a perceived desirable or undesirable feeling are used to get away from defining the experience as an emotion, or mood ${ }^{1}$. Assessment of satisfaction within this domain relates specifically to pregnancy and satisfaction with pregnancy. To identify the aspects of pregnancy that impact on affect and satisfaction we conducted three focus groups. Two groups were with women who had recently given birth ( $n=9$ and $n=10)$ and one with women who were pregnant $(n=9)$. Twenty eight women participated in the focus groups and their characteristics can be found in Table 1. Women were recruited via a local pregnancy yoga group and local SureStart programme. The focus groups were conducted in local community centres by one of the research team (FA). The focus groups lasted for approximately 40 minutes to one hour and took place after their yoga or Surestart meetings 
Table 1: Characteristics of women participating in focus groups $(n=28)$

\begin{tabular}{|l|c|}
\hline Characteristic & Number (\%) \\
\hline Pregnant & $9(32.1)$ \\
Postnatal & $19(67.9)$ \\
\hline Married or living with partner & $26(92.6)$ \\
\hline Age & $2(7.1)$ \\
20 or under & $5(17.9)$ \\
$21-25$ & $9(32.1)$ \\
$26-30$ & $6(21.4)$ \\
$31-35$ & $6(21.5)$ \\
$36-40$ & 0 \\
Over 40 & $13(46.4)$ \\
\hline Education & $4(14.3)$ \\
Up to GCSE or equivalent & $11(39.3)$ \\
Up to A Level or equivalent & $1(3.6)$ \\
University qualification & $24(85.7)$ \\
\hline Country of birth & $2(7.1)$ \\
Northern Ireland & $1(3.6)$ \\
Republic of Ireland & \\
Britain & \\
Missing & \\
\hline
\end{tabular}

Participants in the focus groups completed the European Social Survey Well-being Scale Women were asked about their overall impression of the questionnaire and if they felt the questions were relevant to them. Women were then asked about their well-being in pregnancy: 
what makes/made you happy, what is/ was bad or made you unhappy about pregnancy. Focus groups were coded using content analysis with data being grouped into categories and then themes ${ }^{2}$. Table 2 highlights the themes and some quotations from women in relation to those themes.

Information from descriptive studies of women's experiences of pregnancy and antenatal care that were ultimately included in a review of pregnancy specific stress measures ${ }^{3}$ were also used to facilitate the focus groups and question development. The questionnaire was then tested on five pregnant women for clarity and content and no changes were required.

Building on the focus group themes the measure is made up of 12 pregnancy-specific items. The experience of health professionals theme was developed into two questions to highlight the satisfaction and support aspects of care. A frequency scale was used as frequency measures have been demonstrated to be theoretically and empirically robust when measuring positive and negative affect ${ }^{1}$. Women were asked to respond to each item using a 6 point scale ranging from 'all the time' to 'at no time' which is similar to the WHO 5 scale. The timeframe was experience during current pregnancy. 
Table 2: Themes from focus groups

\begin{tabular}{|c|c|}
\hline 'Theme & Quotation \\
\hline $\begin{array}{l}\text { Response to general } \\
\text { well-being } \\
\text { questionnaire }\end{array}$ & $\begin{array}{l}\text { 'They were kind of important questions I thought ' } \\
\text { 'A bit biased in favour of people who don't have children' } \\
\text { 'I'd maybe tailor the sleep and social aspects ' } \\
\text { 'What was missing: I think worry, talking about worry, like I } \\
\text { worried an awful lot, ' } \\
\text { 'I was like worried over everything... niggle niggle everything ' } \\
\text { 'The question about physical activity you know - can't wait and } \\
\text { do a spinning class but haven't been able to do one for quite a } \\
\text { long [time]' }\end{array}$ \\
\hline Relationships & $\begin{array}{l}\text { 'That's my biggest worry of pregnancy is how its going to affect } \\
\text { my married life.' } \\
\text { 'You worry about how other people, how other people } \\
\text { perceive you and what you do afterwards' } \\
\text { 'Yes I worried about me and my partner' }\end{array}$ \\
\hline Giving birth & $\begin{array}{l}\text { 'Giving birth is in there ' } \\
\text { 'I would say you think about birth before you even get } \\
\text { pregnant....' } \\
\text { 'I'm just worried about getting it out.' } \\
\text { 'About the delivery and was everything going to be alright' }\end{array}$ \\
\hline My health & $\begin{array}{l}\text { 'Like thinking, oh, I can't lift that or I can't eat that and 'Is this } \\
\text { ok?' } \\
\text { 'The whole pregnancy was like a ticking time bomb the whole } \\
\text { time' }\end{array}$ \\
\hline $\begin{array}{l}\text { How I look in } \\
\text { pregnancy }\end{array}$ & 'I do feel quite proud of my bump’ \\
\hline
\end{tabular}




\begin{tabular}{|c|c|}
\hline & $\begin{array}{l}\text { 'Because I am battling weight all the time, but when you're } \\
\text { pregnant you don't care' } \\
\text { 'I liked the bump, I felt so pretty' }\end{array}$ \\
\hline Physical symptoms & $\begin{array}{l}\text { 'I think the nauseousness was worse [than being sick]' } \\
\text { 'It was the tiredness that got me. I was floored by it ' } \\
\text { 'My shoes wouldn't fit me or nothing' } \\
\text { 'I had a lot of fluid so I just felt quite fat' }\end{array}$ \\
\hline $\begin{array}{l}\text { Feelings about } \\
\text { pregnancy }\end{array}$ & $\begin{array}{l}\text { 'I enjoyed being pregnant' } \\
\text { 'I hated being pregnant' } \\
\text { 'You're the princess' } \\
\text { 'I would be pregnant all day long. All my life I would be } \\
\text { pregnancy' }\end{array}$ \\
\hline Attachment baby & $\begin{array}{l}\text { 'You feel happy about it once you start feeling the baby move' } \\
\text { 'With my second one I worried that I would not love him as } \\
\text { much as I loved the first one' } \\
\text { 'All of a sudden I went 'Am I going to want my baby?' ' }\end{array}$ \\
\hline Health of baby & $\begin{array}{l}\text { 'And that they're safe, that they're healthy' } \\
\text { '[Worried] baby healthy...' }\end{array}$ \\
\hline $\begin{array}{l}\text { Experience of health } \\
\text { care/health } \\
\text { professionals }\end{array}$ & $\begin{array}{l}\text { 'Well I was worried sick because they kept going 'Listen, you're } \\
\text { going to need a section' and I kept saying to them 'But I've } \\
\text { never had a baby before how do you know?' } \\
\text { 'It was only til the doctor came and then he explained the } \\
\text { situation' } \\
\text { 'Why ask women what kind of birth plan they want when } \\
\text { usually maybe the opposite happens ' }\end{array}$ \\
\hline $\begin{array}{l}\text { Confidence/sure of } \\
\text { yourself }\end{array}$ & $\begin{array}{l}\text { 'I loved walking into a room and everybody know that I was } \\
\text { pregnant' } \\
\text { 'I felt I was blossoming' }\end{array}$ \\
\hline Purpose in life & 'I hadn't thought of purpose in life before now' \\
\hline
\end{tabular}




\section{References}

1. Diener, E, Napa Scollon C, Lucase RE. The Evolving Concept of Subjective Wellbeing: The Multifaceted Nature of Happiness. in Diener E (Ed) Assessing Well-being Social Indicators Research Series 2009 Number 39 Springer USA.

2. Morse J M and Field P A (1995). Qualitative research methods for health professionals. Sage Publications, London

3. Alderdice F, Lynn F, Lobel M. A review and psychometric evaluation of pregnancyspecific stress measures. Journal of Psychosomatic Obstetrics and Gynecology 2012;33:62-77. doi:10.3109/0167482X.2012.673040

4. Bech P. Measuring the Dimension of psychological general well-being by the WHO-5.Quality of Life Newsletter 200432 15-16. 
Supplementary File 2: Associations between well-being in pregnancy, general well-being and perinatal outcomes

The study also explores if well-being in pregnancy is a better predictor of pregnancy and birth outcomes than general well-being measures. Additional data were collected on self-reported health problems during pregnancy, gestational age at birth, birthweight and admission to special care. Multiple regression analyses were used to explore the association between pregnancy specific well-being, general well-being and these perinatal outcomes. The odds ratios are expressed as a 1 SD change in the WiP rather than in terms of the actual scale values for ease of interpretation.

Associations between the WiP subscales, a composite General Well-being score and outcomes of pregnancy and birth were explored to investigate anticipated relationships between health and well-being. With the exception of self-reported health problems during pregnancy $(n=318)$, regressions were conducted on the 267 participants for whom information on live births could be identified at time of data collection through linkage with the hospital routine data system. Fifty one women were lost to follow up as key identifier data were not available on the routine data system to facilitate linkage. In these analyses, we used the scores for the two factors derived from the rotated solution of the exploratory factor analysis (while excluding Item 12). The regression models controlled for maternal age, education, marital status and parity, and included the WiP subscales as well as a factor score for general well-being (encompassing ESS, WHO5 and SWLS) to explore unique and common variance. 
The Concerns subscale (inverse coded, whereby higher scores indicated less concerns) was found to have an independent association with self-reported problems during pregnancy (OR 0.69, 95\% $\mathrm{Cl}$ 0.52-0.93: $\mathrm{p}=0.014)$. Association between the two subscales of the WiP and low birthweight (Positive Affect and Satisfaction subscale: OR 0.66, 95\% Cl $0.43-1.03, p=0.065$ and Concerns subscale: OR $0.62,95 \% \mathrm{Cl} 0.38-1.01, \mathrm{p}=0.053$ ) were marginally non-significant. However none of the well-being measures predicted low birthweight when the General Wellbeing score was introduced into the model. The two WiP subscales and the General Well-being score were not associated with pre-term birth or admission to special care. 